\title{
EVALUATION OF THE INTER-REPAIR OPERATION PERIOD OF ELECTRIC SUBMERSIBLE PUMP UNITS
}

\author{
Habibov Ibrahim Abulfaz ${ }^{1}$ \\ h.ibo@mail.ru \\ Abasova Sevinj Malik \\ seva-abasova@mail.ru \\ ${ }^{1}$ Department of Engineering and Computer Graphics \\ Azerbaijan State Oil and Industry University \\ 20 Azadliq ave., Baku, Azerbaijan, AZ 1010
}

\begin{abstract}
In recent years, in the oil and gas industry of Azerbaijan, the use of electric submersible pumps (SEP) as one of the effective way to increase the level of production of well products. Currently, electric centrifugal pumping units (ECPU) are widely used both on land and in offshore fields. Currently, a total of about $15 \%$ of SOCAR's oil wells are produced using electric submersible pumping units.

ECPU effectiveness is largely determined by both the period of their operation and the frequency of repair and restoration work.

It is established that the use of ECPUs contributes to an increase in the service life of equipment and the effectiveness of a mechanized method of oil production. To assess the benefits of the latter, the most important factor is the inter-repair period (Tir) of the equipment.

Existing methods for determining the inter-repair period of oilfield equipment are accompanied by large errors, which significantly reduce their reliability.

In this regard, the article is tasked with developing a more practical and reliable method for determining the inter-repair period, where the point of change in the nature of the failure rate is adopted as the determining parameter.

Keywords: electric submersible pumping units, oil well, repair frequency, failure rate.
\end{abstract}

DOI: $10.21303 / 2461-4262.2020 .001105$

\section{Introduction}

Oil and gas sectors of Azerbaijan are the determining factors of the fuel and energy complex (FEC) of the republic. More than $60 \%$ of the country's budget is formed here and therefore, issues related to improving the efficiency of technological processes and equipment resources used in this industry are relevant.

At present, in the republic's oil producing fields, along with fountain and rod-pumping methods, a production method using electric submersible pumping units is also used. About $15 \%$ of SOCAR's oil wells produce oil using electric submersible pumps (ESP) [1].

Prediction of the time between ESP failures before launching into the well, as well as assessment of its residual life during operation, will determine the operating time to failure, plan repair measures and prevent the maximum wear of their components. One of the main parameters characterizing the performance of oil pumping equipment is their interrepair period.

The aim of research is development of a new solution in the determination of the inter-repair period $\left(T_{i r}\right)$ of electric submersible pumps, using the point of change in the nature of the intensity of their failures.

\section{Theoretical background of the problem}

Field data on malfunctions and premature failure of parts and assemblies of ESPs shows that the nature of their occurrence varies in time and a sharp fracture occurs at a certain point (Fig. 1), which leads to dangerous failures [2]. 


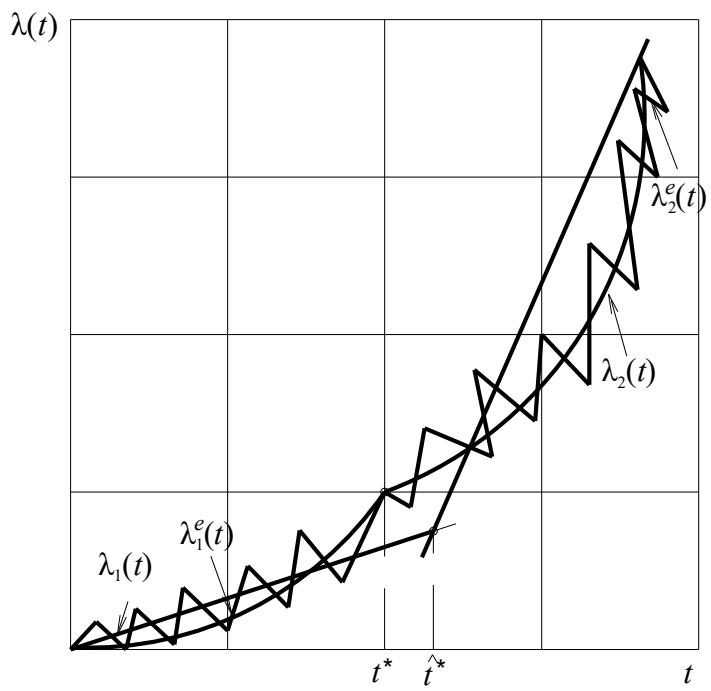

Fig. 1. The nature of the change in the frequency of failures occurring in electric submersible pumps: $\lambda_{1}(t), \lambda_{2}(t)$ - theoretical and $\lambda_{1}^{e}(t), \lambda_{2}^{e}(t)$-empirical failure rates

In the main period of operation, the physics of failures contains elements of both wear-out and sudden failures, but with a large predominance of wear-out gradual failures with some characteristic increasing function of the failure rate $\lambda(t)$. In fact, if the pump element has almost no hidden defects, but it quickly is "aging", then the failure rate and the reliability function $P(t)$, that is, the probability of failure-free operation, should be well approximated by Weibull law with a parameter of $>1$ or a normal law [6].

In the case when the consequences of failures can be the occurrence of dangerous situations and injuries of staff, existing in the theory of reliability methods for determining the inter-repair period (IRP), based on the analysis and minimization of operating losses, for example [3-5], become unacceptable.

The results of numerous experiments and analysis of the evaluation data for the operation of electric submersible pumps (ESP) allow to divide the nature of their intensity into two cases: before the point of intensity breakdown and after. In this work, the intensity tipping point $t^{*}$ is determined using the nonlinear corrosion-regression approximation of the empirical intensity functions $\lambda_{1}^{e}(t)$ and $\lambda_{2}^{e}(t)$, respectively, to the fracture point and after. The point $t^{*}$ obtained in [7] using a linear approximation of the above empirical functions is taken as the initial approximation.

After the fracture point, the failure rate increases sharply due to the physico-mechanical and physico-chemical processes occurring in the nodes and parts of the equipment. The frequency of these deviations is described as follows:

$$
\lambda(t)=\frac{f(t)}{1-F(t)}=-\frac{1}{P(t)} \frac{d P(t)}{d t},
$$

where $\lambda(t)$ - the failure rate; $P(t)$ - the probability of failure-free operation associated with the distribution function $F(t)$ and the distribution density $f(t)$ of the time between failures by the ratios:

$$
\begin{gathered}
F(t)=1-P(t) \\
f(t)=\frac{d F(t)}{d t}=-\frac{d P(t)}{d t} .
\end{gathered}
$$

The appearance of dangerous failures is considered to be possible [2], if the ratio of neighboring (at intervals) values of the empirical failure rate satisfies the relation 


$$
\lambda_{2}^{e}(t) / \lambda_{2}^{e}(t) \geq 2
$$

where $\lambda_{1}^{e}(t)$ and $\lambda_{2}^{e}(t)$ - the empirical failure rate before and after the fracture point.

To estimate the value of the point of a breakdown in the failure rate, as a first approximation, it is enough to find the intersection of straight lines, which are linearization of the curves $\lambda_{1}^{e}(t)$ and $\lambda_{2}^{e}(t)$ in the vicinity of the point "suspicious" of the presence of a fracture in the intensity of the failure. Such a point (let's denote it by $\ll t^{*} \gg$ ) must, first of all, satisfy relation (2) and is defined as the intersection point of two linear regressions

$$
\hat{\lambda}_{1}(t)=a_{1} t+b_{1}, \quad \hat{\lambda}_{2}(t)=a_{2} t+b_{2}
$$

coefficients $a_{1}, b_{1}$ and $a_{2}, b_{2}$ are estimated by the method of least squares (OLS).

Equating the left and right sides of equations (3), let's obtain:

$$
\hat{t}^{*}=\left(\hat{b}_{1}-\hat{b}_{2}\right) /\left(\hat{a_{2}}-\hat{a}_{1}\right) .
$$

Substituting the last least-squares equation $\hat{a}_{j}, \hat{b}_{j}$ into the last equation of the coefficient $a_{j}, b_{j}(j=1,2)$, let's reduce to the following formula [7]:

$$
\hat{t^{*}}=\frac{m_{\lambda_{1}}-m_{\lambda_{2}}+\left(\frac{k_{\lambda_{2}}}{D_{2}} \cdot m_{2}-\frac{k_{\lambda_{1}}}{D_{1}} \cdot m_{1}\right)}{\frac{k_{\lambda_{2}}}{D_{2}}-\frac{k_{\lambda_{1}}}{D_{1}}} .
$$

Here

$$
\begin{gathered}
m_{j}=\frac{1}{n_{j}} \sum_{n=1}^{n_{j}} t_{n}^{(j)}, m_{\lambda_{j}}=\frac{1}{n_{j}} \sum_{n=1}^{n_{j}} \lambda_{j}^{e}\left(t_{n}^{(j)}\right), \\
D_{j}=\frac{1}{n_{j}} \sum_{n=1}^{n_{j}}\left(t_{n}^{(j)}-m_{j}\right)^{2}, k_{\lambda_{j}}=\frac{1}{n_{j}} \sum_{n=1}^{n_{j}}\left(t_{n}^{(j)}-m_{j}\right)\left[\lambda_{j}^{e}\left(t_{n}^{(j)}\right)-m_{\lambda_{j}}\right], \quad(j=1,2),
\end{gathered}
$$

$\left\{t_{n}^{(1)}\right\}_{n=\overline{1, n_{1}}}$ and $\left\{t_{n}^{(2)}\right\}_{n=\overline{1, n_{2}}}$ - points from the left-side and right-sided neighborhood of the "suspicious" point $\hat{t}^{*} ;\left\{\lambda_{1}^{e}\left(t_{n}^{(1)}\right)\right\}$ and $\left\{\lambda_{2}^{e}\left(t_{n}^{(2)}\right)\right\}$ - the values of the intensities $\lambda_{1}^{e}(t)$ and $\lambda_{2}^{e}(t)$ at the points $t=t_{n}^{(1)}$ and $t=t_{n}^{(2)}$, respectively. The value $\hat{t}^{*}$ found by formula (4) is taken in [8] as the value of the inter-repair period $T_{i r}$.

The refinement of estimate (4) is achieved by smoothing the intensity curves $\lambda_{1}^{e}(t)$ and $\lambda_{2}^{e}(t)$ by the nonlinear regressions. Let $\tilde{\lambda}_{1}(t)$ and $\tilde{\lambda}_{2}(t)$ be the best nonlinear approximations of functions $\lambda_{1}^{e}(t)$ and $\lambda_{2}^{e}(t)$, obtained using the 2D program. The solution to the $t$ equation

$$
\tilde{\lambda}_{1}(t)=\tilde{\lambda}_{2}(t)
$$

for a given initial approximation $t_{0}=\hat{t}^{*}$, where $\hat{t}^{*}$ is determined by formula (4), it gives a more accurate estimate of the inter-repair period $T_{i r}$. The solution of nonlinear equation (6) for a given initial approximation is easily found using the corresponding program in the MATHCAD or MATLAB system.

It should be noted that when crossing the fracture point $t^{*}$, the form of the distribution function may also change. Then, with the known distribution functions $f_{1}(t)$ and $f_{2}(t)$ before and after the fracture point, the corresponding intensity functions $\lambda_{1}(t)$ and $\lambda_{2}(t)$ are found by formula (1), and instead of equation (6), the equation is solved concerning $t$ 


$$
\lambda_{1}(t)=\lambda_{2}(t)
$$

at the initial approximation $t_{0}=\hat{t}^{*}$, where $\hat{t}^{*}$ is determined by formulas (4)-(6), in which $\lambda_{j}^{\dot{y}}(t)$ is replaced by $\lambda_{j}(t)(j=1,2)$.

In particular, for the exponential distribution law with distribution density

$$
f(t)=\left\{\begin{array}{lll}
0 & \text { at } & t<0, \\
\lambda e^{-\lambda t} & \text { at } & t \geq 0
\end{array}\right.
$$

failure rate

$$
\lambda(t) \equiv \lambda
$$

For a truncated normal distribution law with a distribution density

$$
f(t)=\frac{C}{\sigma \sqrt{2 \pi}} \exp \left\{-\frac{\left(t-a_{0}\right)}{2 \sigma^{2}}\right\}, C=1 / \Phi\left(\frac{a_{0}}{\sigma}\right)
$$

where

$$
\Phi(x)=\int_{-\infty}^{x} \frac{1}{\sqrt{2 \pi}} e^{-\frac{1}{2} \xi^{2}} \mathrm{~d} \xi
$$

is the distribution function of the standard normal law, the failure rate is determined by the formula

$$
\lambda(t)=\phi\left(\frac{t-a_{0}}{\sigma}\right) /\left[\sigma \Phi\left(\frac{a_{0}-t}{\sigma}\right)\right], \varphi(x)=\frac{1}{\sqrt{2 \pi}} e^{-\frac{1}{2} x^{2}} ;
$$

for Weibull distribution with distribution density

$$
f(t)=\lambda b t^{b-1} \exp \left\{-\lambda t^{b}\right\}, \lambda=\frac{1}{a},
$$

failure rate

$$
\lambda(t)=\lambda b t^{b-1}
$$

\section{Research results}

In this case, statistics $v=\frac{r}{N}$, are used where $r$ - the number of failed samples for the running time $t$ of the $N$ samples put to the test, and the probability of failure-free operation $P(t)$ is related to $v$ by the ratio $P(t)=1-v$.

The reliability characteristic determined by the value $v$ is sufficient statistics [6]. This means that knowledge of any other statistics (that is, a random variable depending on the sampled data) does not add anything to the knowledge of probability $P(t)$, obtained on the basis of statistics $\vee[10,13]$.

Statistical processing of volume data $n=12$ from the last column of Table 1 shows that they obey the truncated normal distribution law $(N)$ with $a_{0}=0.636$ and $\sigma=0.336$ or the Weibull distribution $(W)$ with $\hat{a}=1.2969$ and $\hat{b}=1.9470$.

Let's denote $\beta=1 / b$ and $\hat{\beta}=1 / \hat{b}$, where $\hat{b}=1.9470$ - the parameter $b$ estimate obtained in [9] using nonlinear regression. Confidence limits for the true value of the parameter $b$ can be obtained using statistics $W=\hat{\beta} / \beta$, from the table of values of which are given in [11]. It is possible to select such statistics $W$, values for example, $W_{1-\alpha / 2}$ and $W_{\alpha / 2}$, that 


$$
P\left\{W_{1-\alpha / 2} \leq \frac{\hat{\beta}}{\rho} \leq W_{\alpha / 2}\right\}=1-\alpha .
$$

Table 1

Statistical indicators of submersible ESP failures

\begin{tabular}{|c|c|c|c|c|c|c|}
\hline \multirow{3}{*}{$\begin{array}{l}\text { Operating } \\
\text { interval, days }\end{array}$} & \multicolumn{5}{|c|}{ The number of failures by category of wells } & \multirow{3}{*}{$\begin{array}{l}\text { The number of failures in } \\
\text { the operating time interval }\end{array}$} \\
\hline & \multirow{2}{*}{ normal «N» } & \multirow{2}{*}{ sand $« S »$} & \multirow{2}{*}{ corrosion $« \mathrm{C} »$} & \multicolumn{2}{|c|}{ corrosion-sand } & \\
\hline & & & & «CS» & «CS'» & \\
\hline $0-15$ & - & - & 22 & 38 & & 60 \\
\hline $15-30$ & - & - & 28 & 87 & 10 & 125 \\
\hline $30-45$ & - & 19 & 30 & 90 & 30 & 169 \\
\hline $45-60$ & 15 & 23 & 26 & 70 & 36 & 170 \\
\hline $60-75$ & 20 & 30 & 12 & 40 & 44 & 146 \\
\hline $75-90$ & 35 & 34 & - & 8 & 28 & 105 \\
\hline $90-105$ & 45 & 29 & 6 & 5 & 15 & 100 \\
\hline $105-120$ & 60 & 22 & - & - & 4 & 86 \\
\hline $120-135$ & 48 & 18 & - & - & - & 66 \\
\hline $135-150$ & 43 & 12 & - & - & - & 55 \\
\hline $150-165$ & 37 & 5 & 4 & - & - & 46 \\
\hline $165-180$ & 24 & - & - & - & - & 24 \\
\hline $180-195$ & 327 & 192 & 128 & 338 & - & 1,152 \\
\hline
\end{tabular}

This inequality can be rewritten in the form

$$
\frac{\hat{\beta}}{W_{\alpha / 2}} \leq \beta \leq \frac{\hat{\beta}}{W_{1-\alpha / 2}}
$$

where the $100-(1-\alpha) \%$ two-sided confidence boundaries for the parameter $b$ of the Weibull distribution are:

$$
\hat{b} \cdot W_{1-\alpha / 2} \leq b \leq \hat{b} \cdot W_{\alpha / 2}
$$

Assuming $\alpha=0.1$, from [11] let's find for $n=12$ and $r=12$ and $W_{0.95}=1.60$. Therefore, for the example under consideration with a confidence probability $P=0.9$, the true value of the parameter satisfies the inequality

$$
0.60 \cdot 1.9470 \leq b \leq 1.35 \cdot 1.9470
$$

so

$$
1.1682 \leq b \leq 2.6284
$$

The failure rate, obeying the Weibull distribution c $b>2$, tends to increase sharply. Since in our example the parameter $b$, according to (14) can have a value greater than 2 , dangerous failures can occur. 


\section{Discussion of research results}

Based on the experimental data, a series of failure values of submersible ESPs is constructed, which is presented below:

$60 ; 125 ; 169 ; 170 ; 146 ; 105 ; 100 ; 86 ; 66 ; 55 ; 46 ; 24$.

A series of statistics $v$ corresponds to series (15) (the failure rate $r$ among the total number of pumps $N=1152$ ).

$$
\begin{gathered}
0.0521 ; 0.1085 ; 0.1467 ; 0.1475 ; 0.1267 ; 0.0911 ; \\
0.0868 ; 0.0746 ; 0.0573 ; 0.0477 ; 0.0399 ; 0.0208 \text {. }
\end{gathered}
$$

Having ordered series (16) by increasing its members, let's obtain the so-called variational series:

$$
\begin{array}{r}
0.90208 ; 0.0399 ; 0.0477 ; 0.0521 ; 0.0573 ; 0.0746 ; \\
0.0868 ; 0.0911 ; 0.1085 ; 0.1267 ; 0.1467 ; 0.1475
\end{array}
$$

As shown in [9], a number of developments (15) up to $t=86$ are rather well described by the normal distribution with parameters $\mathrm{a}_{0}=0.636$ and $\sigma=0.336$, and after $t=86$ - by the Weibull distribution with parameters $a=1.2969$ and $b=1.9470$.

Let's take the point $t=86$ or, which is the same thing, $v=0.673$ for the suspicious point of fracture of the failure rate. Let's assume that up to the point $v^{*}=0,673$, the statistics $v$ obeys the truncated normal law

$$
f_{1}(v)=\phi\left(\frac{v-a_{0}}{\sigma}\right) /\left[\sigma \Phi\left(\frac{a_{0}}{\sigma}\right)\right]
$$

with parameters $\mathrm{a}_{0}=0.636$ and $\sigma=0.336$ and with intensity

$$
\lambda_{1}(v)=\phi\left(\frac{v-a_{0}}{\sigma}\right) /\left[\sigma \Phi\left(\frac{a_{0}-v}{\sigma}\right)\right],
$$

and after the point $v^{*}=0.673$ - to the Weibull distribution with density

$$
f_{2}(v)=\frac{b}{a} v^{b-1} \exp \left\{-\frac{b}{a} v^{b}\right\}
$$

with parameters $\hat{a}=1.2969$ and $\hat{b}=1.9470$ and intensity

$$
\lambda_{2}(v)=\frac{b}{a} v^{b-1}
$$

Regression equations for statistics $v$ can be written as

$$
\hat{\lambda}_{1}(v)=a_{1} v+b_{1}, \quad \hat{\lambda}_{2}(v)=a_{2} v+b_{2}
$$

For the left-sided neighborhood of the point $v^{*}=0.673$, points from the sequence are taken

$$
\left\{v_{n}^{(1)}\right\}_{n=1, n_{1}}=\{0.0521 ; 0.161 ; 0.303 ; 0.455 ; 0.582 ; 0.673\} \quad\left(n_{1}=6\right),
$$

and for the right-hand neighborhood - points from the sequence 


$$
\left\{v_{n}^{(2)}\right\}_{n=\overline{1, n_{2}}}=\{0.673 ; 0.759 ; 0.839 ; 0.891 ; 0.939 ; 0.979 ; 1.0\} \quad\left(n_{2}=7\right)
$$

The function $\Phi(x)$ is calculated by the approximate formula [12]

$$
\Phi(x)=1-\phi(x) \cdot \sum_{i=1}^{3} \alpha_{i} \xi^{i}
$$

where

$\xi=1 /(1+p \cdot x), \quad p=0.33267, \alpha_{1}=0.4361836, \alpha_{2}=-0.1201676, \alpha_{3}=0.9372980$.

The error of formula (23) is estimated as

$$
|\varepsilon(x)| \leq 10^{-5} .
$$

Equation solution

$$
\lambda_{1}(v)=\lambda_{2}(v)
$$

where $\lambda_{1}(v)$ and $\lambda_{2}(v)$ are represented by formulas (19) and (21), respectively, under the initial condition $v_{0}=v^{*}=0.576$ gives

$$
v^{*}=0.612 \text {, }
$$

which corresponds to the operating time

$$
t^{*}=90 \text {. }
$$

Since $t^{*}=90$ is the end of the time interval $[75,90]$, which corresponds to the intensity $v=0.582$, the closest to the value $v^{*}=0.612$ and not exceeding $v^{*}$ the value $t^{*}$, determined by value (26) is taken as the value of the inter-repair period $\mathrm{T}_{i r}$.

Table 2 shows the data on the average $\left(T_{a v}\right)$ and maximum $\left(T_{\max }\right)$ inter-repair periods for the operation of ESP-type submersible units in various oil and gas production units for Azneft. As can be seen from the Table 2 experimental data on the average $T_{a v}$ value of the inter-repair period for

\begin{tabular}{|c|c|c|c|c|c|c|c|c|c|c|c|c|}
\hline \multirow{3}{*}{$\begin{array}{c}\text { Name of «Azneft» oil } \\
\text { and gas production } \\
\text { units }\end{array}$} & \multicolumn{12}{|c|}{ Standard sizes of ECPU submersible units and information on $T_{a v}$ and $T_{\max }$ (in days) } \\
\hline & \multicolumn{3}{|c|}{ ECPU-5-200 } & \multicolumn{3}{|c|}{ ECPU-6-160 } & \multicolumn{3}{|c|}{ ECPU-6-250 } & \multicolumn{3}{|c|}{ ECPU-6-350 } \\
\hline & $\mathbf{n}$ & $\mathbf{T}_{\mathrm{cp}}$ & $\mathbf{T}_{\max }$ & $\mathbf{n}$ & $\mathbf{T}_{\mathrm{av}}$ & $\mathbf{T}_{\max }$ & $\mathbf{n}$ & $\mathbf{T}_{\mathrm{av}}$ & $\mathbf{T}_{\max }$ & $\mathbf{n}$ & $\mathbf{T}_{\mathrm{cp}}$ & $\mathbf{T}_{\max }$ \\
\hline «Balakhanyneft» OGPU & - & - & - & - & - & - & - & - & - & - & - & - \\
\hline A. D. Amirov OGPU & - & - & - & - & - & - & - & - & - & - & - & - \\
\hline «Surakhanyneft» OGPU & 1 & 63 & 100 & 2 & $54 \ldots 67$ & $89 \ldots 92$ & - & - & - & - & - & - \\
\hline G. Z. Tagiyev OGPU & - & - & - & - & - & - & - & - & - & - & - & - \\
\hline «Bibieybatneft» OGPU & - & - & - & - & - & - & 1 & 66 & 78 & - & - & - \\
\hline Total: & 1 & 63 & 100 & 2 & $54 \ldots 67$ & $89 \ldots 92$ & 1 & 66 & 78 & - & - & - \\
\hline
\end{tabular}
Azneft Production Association of the Azerbaijan Republic using ESP in difficult operating conditions, the $T_{a v}$ is in the range $63 \ldots .100$, which is consistent with our calculated value $t^{*}=90$ days.

Table 2

Data on the average $\left(T_{a v}\right)$ and maximum $\left(T_{\max }\right)$ inter-repair period of operation of EDP-type submersible units in various oil and gas production units for Azneft 


\section{Conclusions} efficient.

1. The use of electric submersible pump units in oil production is promising and is highly

2. The indicator of the inter-repair period $\left(T_{i r}\right)$ of equipment is a generalizing parameter characterizing the performance of electric submersible pumps.

3. The proposed method for assessing the inter-repair period of operation of electric submersible pump units is practical and can be used in engineering tasks related to the analysis of the reliability of technical equipment.

\section{References}

[1] Lea, J. F., Rowlan, L. (2019). Electrical submersible pumps. Gas Well Deliquification, 237-308. doi: https://doi.org/10.1016/ b978-0-12-815897-5.00012-3

[2] Stel, H., Sirino, T., Ponce, F. J., Chiva, S., Morales, R. E. M. (2015). Numerical investigation of the flow in a multistage electric submersible pump. Journal of Petroleum Science and Engineering, 136, 41-54. doi: https://doi.org/10.1016/j.petrol.2015.10.038

[3] Delou, P. de A., de Azevedo, J. P. A., Krishnamoorthy, D., de Souza, M. B., Secchi, A. R. (2019). Model Predictive Control with Adaptive Strategy Applied to an Electric Submersible Pump in a Subsea Environment. IFAC-PapersOnLine, 52 (1), 784-789. doi: https://doi.org/10.1016/j.ifacol.2019.06.157

[4] E Ofuchi, E. M., Stel, H., Vieira, T. S., Ponce, F. J., Chiva, S., Morales, R. E. M. (2017). Study of the effect of viscosity on the head and flow rate degradation in different multistage electric submersible pumps using dimensional analysis. Journal of Petroleum Science and Engineering, 156, 442-450. doi: https://doi.org/10.1016/j.petrol.2017.06.024

[5] Egidi, N., Maponi, P., Misici, L., Rubino, S. (2012). A three-dimensional model for the study of the cooling system of submersible electric pumps. Mathematics and Computers in Simulation, 82 (12), 2962-2970. doi: https://doi.org/10.1016/j.matcom.2012.05.014

[6] Gnedenko, B. V., Belaev, Yu. K., Solov'ev, A. D. (1965). Matemaicheskie metody v teorii nadezhnosti. Moscow: Nedra, 524.

[7] Babaev, S. G. (1987). Nadezhnost' neftepromyslovogo oborudovaniya. Moscow: Nedra, 264.

[8] Atnagumov, A. R., Ishemchuzhin, I. E. (2010). Prognozirovanie narabotki na otkaz elektrotsentrobezhnogo nasosa pered spuskom v skvazhinu i otsenka ego ostatochnogo resursa pri ekspluatatsii. Neftyanoe hozyaystvo, 6, 102-104.

[9] Gabibov, I. A., Abasova, S. M. (2012). Otsenka veroyatnosti bezotkaznoy raboty pogruzhnyh elektronasosov na osnove issledovaniya svoystv dostatochnoy statistiki. Uchenye zapiski Azerb. Gos. Morskoy Akademii, 2, 60-71.

[10] Kendall, M., Styuart, A. (1973). Statisticheskie vyvody i svyazi. Moscow: Nauka, 899.

[11] Kapur, K., Lamberson, L. (1980). Nadezhnost' i proektirovanie sistem. Moscow: Mir, 604.

[12] Ayvozyan, S. A., Enyukov, I. S., Meshalkin, L. D. (1983). Prikladnaya statistika: Osnovy modelirovaniya i pervichnaya obrabotka dannyh. Moscow: Finansy i statistika, 471.

[13] Kirvelis, R., Davies, D. R. (2003). Enthalpy Balance Model Leads to more Accurate Modelling of Heavy Oil Production with an Electric Submersible Pump. Chemical Engineering Research and Design, 81 (3), 342-351. doi: https://doi.org/ $10.1205 / 02638760360596892$ 